\title{
THE COMPLEMENT FIXATION REACTION OF THE BLOOD OF CHILDREN AND INFANTS, USING THE BACILLUS ABORTUS AS ANTIGEN *
}

\author{
W. P. LARSON, M.D., AND J. P. SEDGWICK, M.D. \\ MINNEAPOLIS
}

The passage of substances through the intestinal wall, and the effect of the ingestion of biologically active bodies on the reactions in the blood and other tissues has been a subject of much interest to many, and especially so to pediatrists. We hope to throw some light on this problem by the demonstration of the fact that a specific reaction can be obtained in the blood of a considerable number of children.

The specific reaction in question is that of the complement fixation test, using the bacillus of infectious abortion of cattle as an antigen. The significance of this particular reaction becomes apparent when we consider that epidemic abortion is common among cattle; that the presence of the Bacillus abortus can be demonstrated in cow's milk, and that the reaction is seemingly specific.

The discussion concerning the enteral absorption of homologous or heterologous proteins has been, and still is, of great interest, but if we turn at once to the subject of the effect of the ingestion of biologically active substances, such as toxins and antitoxins joined with proteins, several illuminating studies are at our disposal.

Römer was able to show in 1901 that a colt, the blood of which at birth was found to be antitoxin-free, and which was fed with its mother's milk which contained diphtheria antitoxin, then gave proof of having antitoxin in its own blood. After the twelfth day, however, no further antitoxin absorption could be demonstrated, and the antitoxin content of the colt's serum then rapidly decreased.

This is of especial interest in connection with the position taken by von Behring concerning other proteins and the tuberculosis question, suggesting the greater possibility of absorption of such products by the new-born.

* Read before the Chicago Pediatric Society, April 21, 1913, and before the American Association of Medical Milk Commissions, at the Seventh Annual Meeting, held at Minneapolis, June, 1913.

* Attention is directed to the paper of Dr. E. C. Schroeder in this issue containing comments on Bacillus abortus.

1. Römer: Untersuchungen über die intrauterine und extrauterine Antitoxinübertragung von der Mutter auf ihre Deszendenten, Berl. klin. Wchnschr., 1901, xxxviii, 1150. 
Salge $^{2}$ gave antitoxic horse serum by mouth to human infants. In no instance was he able to demonstrate the passage of the antitoxin into the infants' blood, even in the new-born. When, however, the antitoxic horse serum was injected subcutaneously into the mother or nurse, and the child put to the breast, the passage of the antitoxin to the child's blood could be shown.

Uffenheimer experimented with the administration of serum-hemolysin, casein, egg-albumin, diphtheria and tetanus antitoxins, by mouth, to new-born guinea-pigs. The hemolysin and casein did not pass over. The egg-albumin could be demonstrated in traces only. The antitoxins could, however, be demonstrated in the blood of the new-born pigs.

The recent work of Hehn taken with that of Lust ${ }^{3}$ indicates that antitoxins in heterologous serums are absorbed more readily in certain diseased conditions of the alimentary tract.

As the infectious abortion of cattle is a condition which, although well known to veterinarians, has but recently appeared in medical literature, a discussion of the condition may be of value.

The Bacillus abortus, often referred to in the literature as the coccobacillus of Bang, was discovered in 1896 by Bang and Stribolt of Copenhagen.

Epizootic abortion has for the past century been the greatest curse with which stock-breeders and dairymen have had to contend. For nearly one century scientific men have recognized the contagious character of this disease, but thus far no advance has been made by way of combating contagious abortion either prophylactically or therapeutically.

With the dawn of the bacteriologic era began the hunt for the etiologic agent of contagious abortion. Men so eminent as Nocard worked on the problem not less than three years without being able to throw any light on its etiology.

The discovery of Bang ${ }^{4}$ and Stribolt was soon confirmed by Stockman and McFadyean ${ }^{5}$ of Great Britain and Nowak ${ }^{6}$ of Austria, and more recently the cocco-bacillus of Bang has been found in this country.

\section{BACILLUS ABORTUS BANG}

Bang's bacillus belongs to the smallest of the visible micro-organisms, measuring from 1 to 2 microns in length. It is a non-motile, non-sporebearing cocco-bacillus, one diameter being only slightly greater than the

2. Salge: Immunisierung durch Milch, Jahrb. f. Kinderh., 1905, lxi, 486.

3. Lust: Die Durchlässigkeit des Magendarmkanals für heterologes Eiweiss bei ernährunggestörten Säuglingen, Jahrb. f. Kinderh., 1913, lxxvii, 243.

4. Bang: Ztschr. f. Tiermed., 1897, i;Maanedskrift f. Dyrlaeger, 1900.

5. McFadyean and Stockman: Report of Committee to Inquire Into Epizootic Abortion, London, 1909.

6. Nowak: Ann. de. l'Inst. Pasteur., 1908, xxii, 541. 
other. It may readily be stained by any of the ordinary anilin dyes, but is Gram-negative.

The micro-organism in question will grow on any of the ordinary culture media after it has once been cultivated in the laboratory. Bang and Stribolt noticed that the growth of the Bacillus abortus appeared a few millimeters beneath the surface of the culture medium and hence concluded that it was a semi-aerobe, developing only at such a point as presented a given oxygen pressure. These authors made the further observation that after this micro-organism had once been cultivated in the laboratory succeeding generations thrived best in an atmosphere of nearly pure oxygen.

McFadyean and Stockman found that the Bacillus abortus could be cultivated successfully when grown in symbiosis with the Bacillus subtilis. These authors assumed that the $B$. subtilis by absorbing a part of the oxygen contained in the closed chamber created a favorable atmosphere for the development of the $B$. abortus. If the observations of these European authors are correct relative to the $B$. abortus in its relation to oxygen, we have here a phenomenon quite unique. It seems strange that an organism which in the first generation develops only under conditions of diminished oxygen pressure should swing to the opposite extreme in the succeeding generation.

There is another possible explanation of this, however.

All who have worked with this organism will agree that the growth of the first generation on artificial media is slow. The colonies, as a rule, do not appear until at the end of the fourth or fifth day, and sometimes even eight to ten days may elapse before the growth becomes apparent. During this time the surface of the culture medium has a tendency to dry out and the growth appears deeper probably because of its demand for moisture.

We have further found that the $B$. abortus grows very well on the surface of ordinary slant agar provided the tube is well sealed with paraffin to prevent evaporation. In a previous paper ${ }^{7}$ we have expressed the view that this might be explained by the fact that agar absorbed a part of the oxygen contained in the tube, thus creating a favorable environment for the development of the B. abortus.

When Bang's bacillus has once been cultivated in the laboratory it grows readily on any of the ordinary media.

The isolation of the $B$. abortus presents but few difficulties. It will, as a rule, be found in pure culture in the gastro-intestinal tract of the fetus provided this is obtained within a few hours after it has been expelled.

7. Larson, W. P.: Jour. Infect. Dis., 1912, x, 178. 
TECHNIC OF CULTIVATION OF B. ABORTUS

The technic we employ is to inoculate tubes of slant agar, preferably ascitic agar or serum agar, from the gastro-intestinal tract of the fetus, and either seal the tubes with paraffin or place in a closed flask together with a few tubes of slant agar freshly inoculated with the $B$. subtilis. On the fourth or fifth day, occasionally on the third day, the growth on the surface of the medium is apparent in the form of small dewdrop-like colonies, which at first remain isolated, but in the course of the next few days become confluent. The $B$. abortus does not coagulate milk nor liquefy gelatin. It produces neither acid nor gas on any of the sugar media. On potato it resembles very much the $B$. malleus.

It has until quite recently been held that the bacillus of Bang was not pathogenic for any of the laboratory animals, with the possible exception of mice. The work of Smith and Fabyean ${ }^{8}$ and Schroeder and Cotton ${ }^{9}$ shows that this organism is pathogenic for guinea-pigs. Injected intravenously into pregnant rabbits or guinea-pigs it will of ten interrupt pregnancy.

Smith and Fabyean ${ }^{8}$ have recently found that when injected into the peritoneal cavity of guinea-pigs the bacillus of Bang produces lesions very simjlar to those of tuberculosis. They report observations made on fifty-eight guinea-pigs and they found lesions in the following organs: lymph-nodes, spleen, liver, kidney, testicle, lung, bones. The eyes of some of these animals presented lesions in the form of an opacity of the cornea.

Fabyean ${ }^{10}$ found further that the guinea-pigs thus affected were hypersensitive to a toxin extracted from the cultures of the $B$. abortus, even when injected in small doses, causing the death of the animals in from twelve to forty-eight hours, thus resembling the action of tuberculin when injected into tuberculous animals.

In the summer of 1911 we became interested in contagious abortion of cattle and inaugurated studies of the disease as it affects bovines. Our work was directed mainly toward establishing the identity of the American and European diseases by the complement-fixation method.

$\mathrm{Wall}^{11}$ and Holt, ${ }^{12}$ working in the laboratory of C. 0 . Jensen of Copenhagen, had found that contagious abortion of cattle could be accurately diagnosed by this method.' We were able to confirm their work. We found that antigen prepared from cultures of the $B$. abortus received from Denmark fixed the complement in the presence of serum

8. Smith and Fabyean: Centralbl. f. Bakteriol., lxi, 549.

9. Schroeder and Cotton: Leaflet issued from the Bureau of Animal Industry, 1912.

10. Fabyean: Jour. Med. Research, xxi, 441.

11. Wall: Maanedskrift f. Dyrlaeger, 1910, xxi.

12. Holt: Maanedskrift f. Dyrlaeger, 1911, xxii, 1. 
from an infected animal. Cultures which we isolated from infected material in this country were identified with the Danish organism.

We have, during the past two years, had occasion to examine the blood of several hundred animals and have found the complementfixation method to be a very accurate means of diagnosing this disease.

Epizootic abortion is probably the most prevalent of all animal diseases. There is scarcely a dairy community where the disease has not at some time prevailed. Young heifers of the herd are the first to become infected and abort. Once introduced into a herd it passes from animal to animal until nearly the entire herd has become infected. An animal will usually abort two to three years in succession, after which she is apparently immune, and when not made sterile by the disease, will carry to term. The abortions usually occur from the third to the seventh month of gestation. The general health of the animal is apparently undisturbed by an infection with the Bang bacillus.

It is generally supposed that the male element of the herd transmits the disease from animal to animal, but there is at present no definite proof of this. Cultures made from bulls of infected herds have invariably been negative; likewise blood examinations made on some fifty bulls have all given negative results.

Bang was able to cause cattle, sheep and goats to abort by administering cultures of the organism per os.

Owing to the prevalence of the disease one would naturally expect to find the organism in milk.

In a study of the pathogenic organisms found in milk, Schroeder and Cotton accidentally found the $B$. abortus, but for some time were not able to identify it. They injected milk as obtained on the market into the peritoneal cavity of guinea-pigs and not infrequently found tuberclelike lesions of the abdominal viscera following such injections in about 10 per cent. of the animals thus treated. They finally concluded that the lesions were due to the $B$. abortus.

It has been pretty conclusively demonstrated that all of our domestic animals are susceptible to infection by this organism, although cattle are by far the most frequently affected. Bang found that sheep and goats would abort after being experimentally infected with this organism. Ostertag $^{13}$ isolated the organism from mares which had aborted. The usual laboratory animals are likewise susceptible to this disease. About one year ago we were forced to discontinue our complement-fixation work on this disease owing to the fact that fully 60 per cent of our guinea-pigs gave a positive reaction, in consequence of which their serum could not be utilized as complement.

13. Ostertag: Kolle and Wassermann's Handbuch d. path. Mik. 


\section{HUMAN INFECTION}

While we were making field observations we took particular pains to make inquiries as to whether there had occurred abortions in women who had come in contact with a herd of cattle while an epidemic of contagious abortion prevailed. Such observations would naturally be of but little value unless one had the opportunity of observing a large number of cases. In the limited number we have had occasion to observe, we have recorded cases of abortion of the mother of the household where the ordinary causes, such as lues or injuries, could be definitely excluded. The results of our investigation along this line will be presented in another paper. Suffice it to say that in systematically examining the serum of women who have aborted we have found that a larger number give a positive complement-fixation reaction using the $B$. abortus as antigen than when the ordinary syphilitic antigen is used.

Thus having evidence indicating that humans might become infected with this organism, we proposed to carry our investigation further in the hope of determining whether or not and to what extent the microorganism in question might be of pathological significance to the human family.

As indicated elsewhere in this paper, the bacillus of Bang is somewhat difficult to cultivate, especially when found in impure culture. In view of this fact the ordinary bacteriological procedures did not appeal to us as being the most desirable as exploratory measures; hence we then proposed to push our investigations further by means of the complementfixation reaction.

From the work of Cotton and Schroeder we know that 10 per cent. of market milk contains the Bacillus abortus; there can, therefore, be little doubt that any individual using dairy products is amply exposed to infection. Bang has shown that animals may readily be experimentally infected with this organism by administering it per os. If the $B$. abortus is pathogenic for human beings, as it is for guinea-pigs, and can be transmitted through the digestive tract as is the case with cattle, we would expect infants and children to be the subjects most frequently infected. We have to date examined the blood of 425 children by the complement-fixation method and have found at least some support of the above-expressed hypothesis. Of these 425 cases we found seventy-three positive and 352 negative reactions. In other words, the blood of 17 per cent. contained antibodies against the $B$. abortus. The same technic was used as in the examination of bovine serums. In order to guard against every possible source of error, known positive and known negative bovine serums were invariably used as controls. Our work was not confined to the complement-fixation test, but agglutination tests were made in a large number of cases. We found in working with human serum, as did Holt 
with bovine serum, that the agglutination and complement-fixation tests run parallel.

To further corroborate the evidence that we were dealing with specific antibodies, other methods suggested themselves. In their work on hemolysis, Ehrlich and Morgenroth found that the specific hemolytic antibodies would unite with the washed erythrocytes when the latter were placed in the serum and left for a few hours. By centrifuging this mixture and decanting off the supernatant serum they found that the latter had, by the contact with the blood-cells, been depleted of the hemolytic antibodies. In other words, the antibodies had attached themselves to the blood-cells and been removed with these.

The same is true of the $B$. abortus antibodies. By treating a positive serum with a suspension of the Bang bacillus, the serum, after a few hours' contact, has been found to be negative when separated from the organisms by the centrifuge. If an adequate amount of complement is then added to the sensitized bacilli and incubated for an hour, the complement will become fixed, thus indicating further that we are dealing with specific antibodies.

It behooved us to prove that a positive serum could not be rendered negative through the action of various indifferent bacteria, such as members of the colon typhoid group, the proteus and pyogenic bacteria. During the course of this investigation a large number of positive serums have been treated with one or more of the above-named bacteria, but invariably with a negative result.

The one question which presents itself is: Are these antibodies in the blood of children the result of an active or passive immunity? This question we have found difficult to answer satisfactorily. We recall the experiments of Ehrlich ${ }^{14}$ in which he immunized mice against rizin and abrin, and later gave the young of non-immunized animals to the immune animals and vice versa; he found that the young of non-immune mothers would become immunized against these poisons when allowed to suck the immune animals for a time. If the same law applies to the problem we now have under consideration, we could readily explain our positive reactions on another basis than infection of the individual.

The experiments of Ehrlich show very clearly that immune bodies are excreted in the milk and that these may pass through the mucous membrane of the intestine and reach the blood. Much and Römer, in studying this phenomenon, further conclude that the penetrability of the mucous membrane of the new-born for immune bodies is by far greater than that of adults. These authors found that the source of the milk containing the immune bodies was no insignificant element. The anti-

14. Ehrlich: Ztschr. f. Hyg., 1892, xii. 
bodies contained in milk of a homologous species were absorbed much more readily than when heterologous milk was given.

Attempts were made to demonstrate the $B$. abortus antibodies in milk from cows which had recently aborted, and whose blood serum fixed the complement in high dilutions. Our results have thus far been negative, as large quantities of milk interfere with the reaction.

Attempts to deplete the milk of any eventual antibodies by treating it with an emulsion of the Bang bacillus have likewise failed to give satisfactory positive evidence that such exist in milk. It is very probable that our positive reactions were the result of an active immunity; in other words, due to antibodies generated by the individual examined. It does not necessarily follow that the positive reactions were due to an active infection of the individual. The work of Müller and others indicates that it is possible to immunize an animal by introducing the antigen per os or per rectum, provided large and repeated doses of the antigen are administered.

\section{IMPORTANCE OF HUMAN SUSCEPTIBILITY}

This discovery of so common a reaction in children opens up the opportunity for more study. We have first the problem as to whether this is a passive or active immunity. Then comes the question concerning the process of absorption, together with further theoretical considerations.

To the pediatrist, it is of particular interest that inoculations of guinea-pigs with the $B$. abortus has been shown to produce lesions of the lymph-nodes, spleen, liver, kidney, testicle, lung and bones, and that these lesions are suggestive, anatomically, of those of tuberculosis. These findings of competent observers together with the experience that inoculation may produce epiphyseal enlargements, and our $1^{17}$ per cent. of positive reactions among children with anatomical lesions of the osseous system, most of them with clinical diagnoses of tuberculosis and rickets, indicate very clearly the need of further investigation. 